\title{
Numerical Assessment of a Filtration Experiment Influenced by Microscale Carbon Monoxide Bubbles Arising in Steel Melt
}

\author{
AMJAD ASAD, ${ }^{1,4}$ MARTIN HAUSTEIN,${ }^{1}$ KINNOR CHATTOPADHYAY, ${ }^{3}$ \\ CHRISTOS G. ANEZIRIS, ${ }^{2}$ and RÜDIGER SCHWARZE ${ }^{1}$
}

1.--Institute of Mechanics and Fluid Dynamics, Technische Universität Bergakademie Freiberg, Lampadius-Str. 4, 09599 Freiberg, Germany. 2.-Institute of Ceramic, Glass and Construction Materials, Technische Universität Bergakademie Freiberg, Agricola-Str. 17, 09599 Freiberg, Germany. 3.-Department of Materials Science and Engineering, University of Toronto, Toronto, ON M5S 3E4, Canada. 4.-e-mail: Amjad.Asad@imfd.tu-freiberg.de

A numerical model based on the assumption that carbon monoxide bubbles form due to reaction between carbon and oxygen on the rough surface of inclusions is introduced to investigate the effects on inclusion removal. The proposed numerical model can be used to determine the growth of such carbon monoxide bubbles on an inclusion, which increases the rising velocity of the inclusion to reach the free surface of the melt faster. The results confirm that formation of carbon monoxide bubbles on the surface of inclusions can considerably increase the number of inclusions removed and thereby improve the cleanliness of steel melt.

\section{INTRODUCTION}

In steelmaking, inclusions such as deoxidation products (e.g., alumina) may arise in the steel melt due to different reactions. ${ }^{1,2}$ Such inclusions lower the quality of the cast product considerably. Therefore, it is important to improve the cleanliness of the melt by enhancing inclusion removal to avoid fracture or internal cracks in the final product. Use of ceramic foam filters (CFFs) is considered to be the simplest and least costly way to enhance inclusion removal in the steel industry.

A real steel casting simulator (SCS) is operated at the Technische Universität Bergakademie Freiberg to estimate the efficiency and performance of CFFs under the framework of the Collaborative Research Centre (CRC) $920 .^{3,4} \mathrm{~A}$ CFF is immersed in the melt in the induction crucible furnace (ICF) of the SCS to determine its efficiency and stability under real casting conditions.

The melt flow in such an ICF has often been investigated, both numerically and experimentally. ${ }^{5-22}$ Baake et al. ${ }^{5}$ investigated the flow in an ICF numerically and experimentally, reporting that the standard $k-\varepsilon$ turbulence model can provide good agreement with the time-averaged flow field measured in a reference experiment. However, this model could not predict the low-frequency velocity pulsations that occur in the region between toroidal vortices, which is significant to describe the heat and mass transfer in the ICF. Large-eddy simulation (LES) was shown to be a good choice to describe the heat and mass transfer. ${ }^{8-11}$ Besides simulating the melt flow, transport of inclusions in an ICF and their deposition on the wall of the ICF were investigated by Ščepanskis et al. ${ }^{17,19}$ Asad et al. ${ }^{21}$ simulated the ICF operated at the Technische Universität Bergakademie Freiberg, revealing the effect of the CFF immersed in the melt on the flow in the ICF, as well as the influence of the permeability and position of the filter on the efficiency of the CFF, considering the presence of the CFF using Darcy's law. The numerical model used in that work has been coupled with a pore-scale simulation to determine the efficiency of two CFFs (10 and $20 \mathrm{ppi}$ ), produced in CRC $920 .^{22}$ The filtration efficiency was relatively low compared with that measured experimentally by Storti et al. ${ }^{23,24}$ or Schmidt et al., ${ }^{25}$ even though the duration of the filtration process was longer in the simulation. The considerable difference between the efficiency values determined experimentally and by simulations was attributed by Storti et al. ${ }^{23,24}$ to the fact that reaction between carbon $(\mathrm{C})$ and oxygen $(\mathrm{O})$ takes place to create $\mathrm{CO}$ bubbles in the melt. The bubbles collect on small inclusions, bringing them to the free 
surface of the melt in the crucible. This effect could make a considerable contribution to inclusion removal and melt cleanliness. $\mathrm{CO}$ bubbles can be created on the surface of $\mathrm{Al}_{2} \mathrm{O}_{3}$ inclusions by reaction between $\mathrm{C}$ and $\mathrm{O}$ available in the melt, as explained in the thesis of Rzehak, ${ }^{26}$ who discussed heterogeneous nucleation of $\mathrm{CO}$ bubbles on inclusions in steel melt. Cournil et al. ${ }^{27}$ investigated spontaneous nucleation of bubbles in concave pores on the surface of small $(5 \mu \mathrm{m})$ inclusions under real thermodynamic conditions, claiming that formation of nanobubbles considerably enhanced the agglomeration of inclusions in steel melt. Heterogeneous nucleation of bubbles at a hydrophobic solid wall was observed experimentally by Yang et al. ${ }^{28}$ Lohse et al. ${ }^{29}$ gave an extensive overview on recent findings about nanobubbles at nonwetting surfaces, mentioning that multiple nanobubbles can form simultaneously on a hydrophobic particle, and that nanobubbles can grow to form microbubbles. The resulting increase in buoyancy means that the aggregate (particle and bubble) floats up quickly. Furthermore, formation of such nanobubbles was assumed to enhance particle-particle and particlemicrobubble interactions.

The present article presents a new extension to the numerical model adopted by Asad et al. ${ }^{21,22}$ to consider formation of $\mathrm{CO}$ bubbles on the surface of inclusions. The numerical model is implemented in OpenFOAM. The new implementation accounts for transport of $\mathrm{C}$ from the carbon-bonded filter. Moreover, this implementation can also consider creation of $\mathrm{CO}$ bubbles on the surface of inclusions due to reaction between $\mathrm{C}$ and $\mathrm{O}$ dissolved in the melt. The exact size of the bubble can be determined using this implementation. The results confirm that creation of $\mathrm{CO}$ bubbles on the surface of inclusions indeed improves the cleanliness of the steel melt.

\section{NUMERICAL MODEL}

\section{Flow Field}

In the current work, the melt flow in the ICF is assumed to be incompressible, isothermal, and turbulent. Furthermore, the melt is considered to be a continuous Newtonian phase. Thus, the motion of the melt is described by the spatially filtered equations for mass and momentum conservation:

$$
\begin{gathered}
\nabla \cdot \underline{u}=0 \\
\frac{\partial \underline{u}}{\partial t}+(\underline{u} \cdot \nabla) \underline{u}=-\frac{1}{\rho} \nabla p+\nabla \cdot(v \nabla \underline{u})+\nabla \cdot \underline{\tau}^{S G S} \\
+\underline{F}_{l o r}+\underline{S}_{f i l t e r}+\underline{\phi}
\end{gathered}
$$

where $\rho$ and $v$ are the density and kinematic viscosity of the melt, respectively. $\underline{u}$ denotes the velocity of the melt, and $p$ stands for the pressure. The source term $\phi$ accounts for the interaction between the disperse and continuous phases, defined as

$$
\underline{\phi}=-\frac{1}{V_{\text {cell }}} \sum \underline{F}_{t o t}
$$

Here a loop over all inclusions present in each computational cell is performed, and the total force acting on the inclusions $\underline{F}_{t o t}$ is calculated. $V_{\text {cell }}$ represents the volume of the computational cell. $\underline{F}_{\text {lor }}$ represents the Lorentz force driving the melt in the ICF. $\underline{F}_{l o r}$ results from the interaction between the alternating magnetic field and the induced eddy currents. This force acts on the melt mainly in a thin layer close to the wall of the crucible due to the skin effect. ${ }^{30,31}$ Since the distribution and the calculation of $\underline{F}_{L r}$ are identical to those discussed in Asad et al., ${ }^{2}$ they are neither explained nor presented here, for the sake of brevity. $\underline{S}_{\text {filter }}$ is an additional source term included in Eq. 2 to consider the pressure drop in the CFF. The flow in the filter is calculated according to the Darcy-Forchheimer law. For more details about calculating this term, the reader is referred to Asad et al. ${ }^{22}$ In the present work, implicit large-eddy simulation (ILES) is used to describe the turbulence in the crucible of the ICF. In this method, the subgrid stress tensor $\underline{\underline{\tau}}^{S G S}$ is estimated using a certain numerical scheme for discretization of the convection term in Eq. 2. This means that no explicit turbulence modeling is required here.

\section{Transport of Carbon}

As mentioned above, the surface of a carbonbonded filter, investigated by Storti et al., ${ }^{23}$ is bonded with carbon (C). This leads to the fact that carbon can be dissolved and transported in the melt. Transport of $\mathrm{C}$ is considered using the following equation for the concentration $c\left[\mathrm{~mol} \mathrm{~m}^{-3}\right]$ :

$$
\frac{\partial c}{\partial t}+\underline{u} \nabla \cdot c=\nabla \cdot\left[\left(\frac{v}{S c}+\frac{v_{\mathrm{t}}}{S c_{\mathrm{t}}}\right) \nabla c\right]+S_{\mathrm{k}}
$$

where $v_{\mathrm{t}}$ denotes the turbulent viscosity, which cannot be calculated explicitly in ILES. Therefore, $v_{\mathrm{t}}$ was estimated according to the Smagorinsky subgrid turbulence model. ${ }^{32} S_{\mathrm{k}}$ is a sink term that accounts for the reduction of $c$ because of reaction between dissolved $\mathrm{C}$ and $\mathrm{O}$. The turbulent Schmidt number was assumed to be $S c_{\mathrm{t}}=1$. The Schmidt number Sc is defined as the ratio of the kinematic viscosity $v$ to the diffusion coefficient of carbon in the steel melt $D$ (Table I).

\section{Reaction Model}

A reaction model was developed to consider the reaction between dissolved $\mathrm{C}$ and $\mathrm{O}$ on the surface of inclusions. Figure 1a presents the system of equations implemented in OpenFOAM to take such reaction into account. The model assumes that the reaction between $\mathrm{C}$ and $\mathrm{O}$ dissolved in the melt is first order. ${ }^{33}$ 
In the first step, the current amount of carbon $n_{0}(\mathrm{~mol})$ is calculated depending on the current concentration of carbon $c$ in each cell and the volume of each cell $V_{\text {cell }}$. If there are alumina inclusions in the cell, carbon reacts with oxygen dissolved in the melt, on the surface of inclusions. Then, $n_{0}$ must be decreased to $n$. The reduction in $n_{0}$ is defined as a function of the number of inclusions in the computational cell $n_{p}$, the surface area of an inclusion $A_{p}$, the time step $\Delta t$, and the reaction rate constant $k_{r}$, as determined by Kim et al. ${ }^{33}$ using an order-of-magnitude estimation method. The increase of the bubble size $\Delta V_{b}$ in the cell is then determined according to the reduction in the amount of carbon $\left|n-n_{0}\right|$, the ideal gas constant $R$, and the melt temperature $T$ and pressure $p$. Meanwhile, the increase of the bubble size for each inclusion is calculated as $\Delta V_{b} / n_{p}$. Due to the reaction, the concentration of carbon in the cell decreases. This is included via the sink term $S_{k}$ included in the carbon transport equation (Eq. 4).

Table I. Properties of steel melt and physical parameters used in the simulation

\begin{tabular}{lc}
\hline Properties & \\
\hline Density of melt, $\rho\left(\mathrm{kg} \mathrm{m}^{-3}\right)$ & 7000 \\
Dynamic viscosity of melt, $\mu\left(\mathrm{kg} \mathrm{s}^{-1} \mathrm{~m}^{-1}\right)$ & 0.006 \\
Melt temperature, $T(\mathrm{~K})$ & 1873 \\
Gas constant, $R\left(\mathrm{~kg} \mathrm{~m}^{2} \mathrm{~s}^{-2} \mathrm{~mol}^{-1} \mathrm{~K}^{-1}\right)$ & 8.314 \\
Diffusion coefficient, $D\left(\mathrm{~m}^{2} \mathrm{~s}^{-1}\right)$ & $10^{-835}$ \\
Reaction constant rate, $k_{r}\left(\mathrm{~mol} \mathrm{~m}^{-2} \mathrm{~s}^{-1}\right)$ & $14.9^{33}$ \\
\hline
\end{tabular}

\section{Disperse Phase}

As mentioned above, the model is based on the assumption that $\mathrm{CO}$ bubbles arise directly on the rough surface of an inclusion due to the mentioned reaction. In this model, it is assumed that the resulting $\mathrm{CO}$ bubble (b) deforms to create a shell surrounding the inclusion. This shell can grow, bringing alumina inclusions to the free surface of the melt. The gas volume in the shell corresponds to the volume of the attached gas bubble. The aggregate formed by the alumina inclusion and the shell is represented in this model by an equivalent particle of spherical shape (Fig. 1b). The surface of the equivalent particle is indicated by the dashed blue line in Fig. 1b. The equivalent particle has effective mass $m_{\text {eff }}$, effective volume $V_{\text {eff }}$, effective density $\rho_{\text {eff }}$, and effective diameter $d_{e f f}$ :

$$
\begin{gathered}
V_{b}=V_{b_{0}}+\Delta V_{b} / n_{p} \\
V_{\text {eff }}=V_{b}+V_{i} \\
m_{\text {eff }}=\rho_{b} V_{b}+\rho_{i} V_{i} \\
\rho_{\text {eff }}=\frac{m_{\text {eff }}}{V_{\text {eff }}} \\
d_{\text {eff }}=\left(\frac{6}{\pi} V_{\text {eff }}\right)^{\frac{1}{3}}
\end{gathered}
$$

In this model, the size of the inclusion remains constant during the simulation. Only the bubble size can increase due to the reaction. The increase of

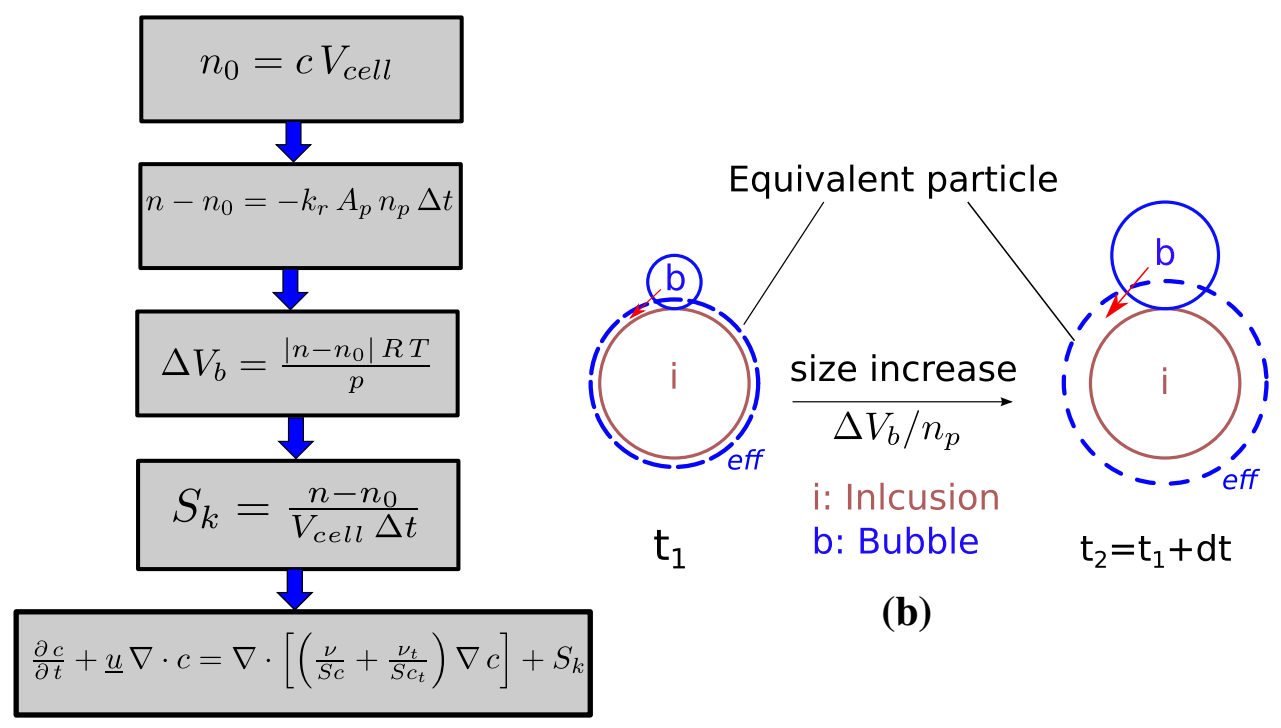

(a)

Fig. 1. Representation of (a) the system of equations implemented in OpenFOAM to account for the reaction between carbon and oxygen and (b) an equivalent particle (eff) consisting of an inclusion (i) of constant diameter and a shell. The volume of the shell corresponds to the volume increase due to the attached $\mathrm{CO}$ bubble (b). 
the bubble size is considered by adding $\Delta V_{b} / n_{p}$ (see Fig. 1a) to the previous bubble volume $V_{b_{0}}$. The density of the bubble $\rho_{b}$ depends on its radius and was calculated during the simulation according to the ideal gas law. The inclusion's density $\rho_{i}$ was assumed to be constant. The effective parameters were then used to predict the forces acting on the equivalent particle. The motion of the equivalent particles was computed from their equations of motion:

$$
m_{e f f} \frac{\mathrm{d} \underline{\mathrm{v}}}{\mathrm{d} t}=\underline{F}_{G}+\underline{F}_{B}+\underline{F}_{D}+\underline{F}_{V M}+\underline{F}_{L}+\underline{F}_{E M}
$$

where $\underline{\mathrm{v}}$ denotes the velocity of an equivalent particle. $\underline{F}_{G}$ and $\underline{F}_{B}$ are the gravity and buoyancy forces, respectively. $\underline{F}_{V M}$ represents the virtual mass force. $\underline{F}_{L}$ represents the lift force. $\underline{F}_{D}$ represents the drag force exerted by the liquid on the equivalent particles. $\underline{F}_{E M}$ is the electromagnetic pressure force acting on the nonconductive equivalent particle (inclusion and bubble). In the simulations, the dispersion model was not used because the inclusions can experience the turbulent fluctuations resolved in the LES simulation. Recently, it was shown that this approach is superior to application of a random walk model with explicit turbulence modeling. ${ }^{34}$ For the sake of brevity, the forces acting on the equivalent particles are not discussed here in detail; the reader is referred to Asad et al. ${ }^{21}$

\section{SIMULATION SETUP}

The geometry of the ICF with the important dimensions is shown in Fig. 2. The computational grid consisted of 4 million cells. In the simulation, $2 \times 10^{6}$ inclusions with diameter of $d_{i}=5 \mu \mathrm{m}$ were inserted randomly from the whole top surface of the melt (free surface) after the melt flow had fully developed. Then, the inclusions were mixed over $30 \mathrm{~s}$ in the melt to ensure a nearly homogeneous distribution throughout the flow field. The inclusion density was assumed to be constant at $\rho_{i}=3200 \mathrm{~kg} \mathrm{~m}^{-3}$. After the inclusions were well mixed in the melt, the filter was immersed in the melt for $10 \mathrm{~s}$. The filter was considered in the simulation as a permanent source of carbon in the filter region. This means that the concentration of carbon was equal to $1 \mathrm{~mol} \mathrm{~m}{ }^{-3}$ during the immersion time of the filter $(10 \mathrm{~s})$. Here, it was assumed that the filter and the filter region were rich in carbon. After $10 \mathrm{~s}$, the filter was removed from the melt and the alternating magnetic field was disabled. The wall of the crucible was considered as a no-slip wall, while the top surface of the melt was assumed to be a slip wall. In the LES, the standard wall functions were not adopted. Moreover, the standard wall functions are not suitable for magnetically driven turbulent flow in the near-wall region. In the case investigated here, the dimensionless distance from the wall $y^{+}$has an averaged

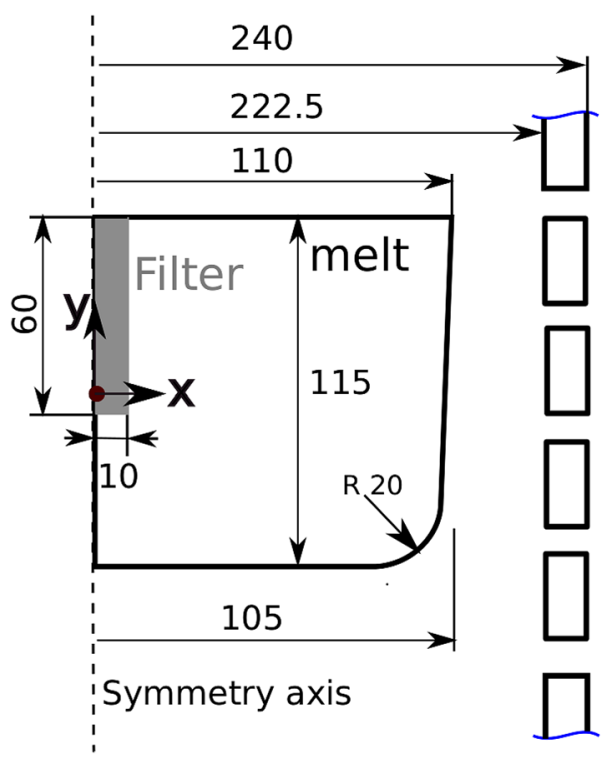

Fig. 2. Axisymmetrical sketch of the investigated induction crucible furnace at Technische Universität Bergakademie Freiberg (units in $\mathrm{mm})$.

value of 1 at the wall of the crucible. This is suitable to ensure a sufficient description of the flow close to the wall in the LES. To reveal the considerable effect of bubble creation, a simulation similar to the adopted setting was performed. However, the flow field and particle distribution are not shown here, due to their similarity to those presented by Asad et al. ${ }^{22}$ Table I summarizes the physical parameters and steel properties used in the simulation.

It was assumed that the initial concentration of $\mathrm{C}$ was zero. Moreover, the initial volume of $\mathrm{CO}$ bubbles on the surface of inclusions was set to be $V_{b}=0$. To focus on the effect of bubble creation, it was assumed that the filter did not capture inclusions.

\section{RESULTS}

Figure 3 compares the distribution of the equivalent particles between two different time steps. $t$ represents the time of the flow simulation after the filter was immersed into the melt, not the reaction time. In this figure, only equivalent particles with diameter $d_{\text {eff }}>d_{i}$ are shown. From this figure, it is evident that the number of equivalent particles with increased effective diameter increased. This can be attributed to the fact that carbon is better transported from the filter to regions far from the filter, enabling the reaction to take place there. Due to the high carbon concentration near to the filter, an equivalent particle can grow and float up quickly to the free surface of the melt. Both equivalent particles and inclusions were removed from the simulation when reaching the free surface of the melt. Inclusions cannot rejoin the flow due to the wetting properties of the free surface of the melt. 


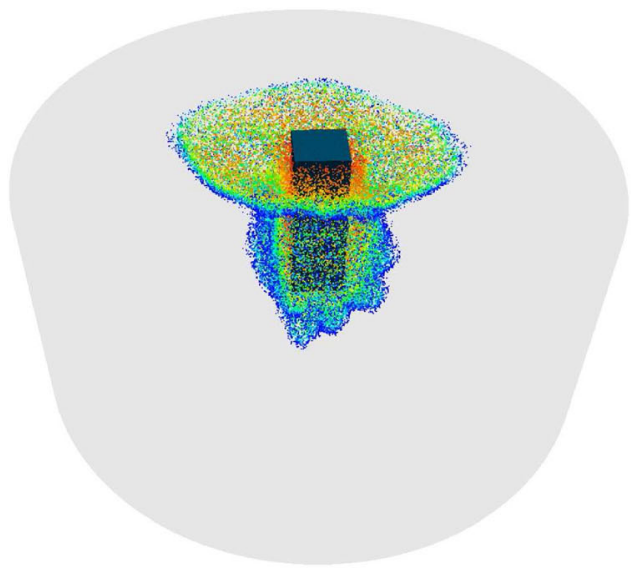

(a)

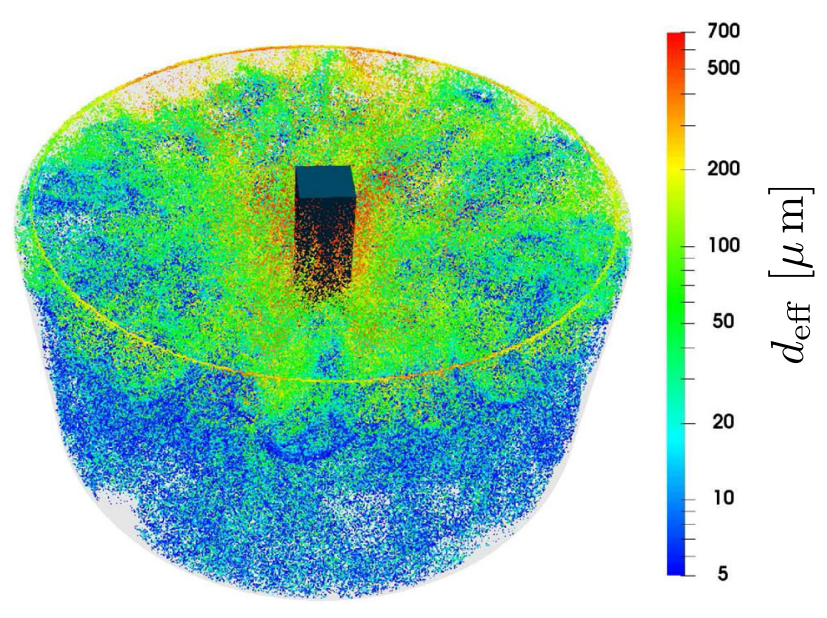

(b)

Fig. 3. Distribution of equivalent particles at different times after immersion of the filter at $t=0 \mathrm{~s}$. The equivalent particles grow because of the reaction between carbon and oxygen. The dark-blue cuboid represents the position of the filter. (a) $t=1 \mathrm{~s}$ and (b) $t=10 \mathrm{~s}$ (Color figure online).
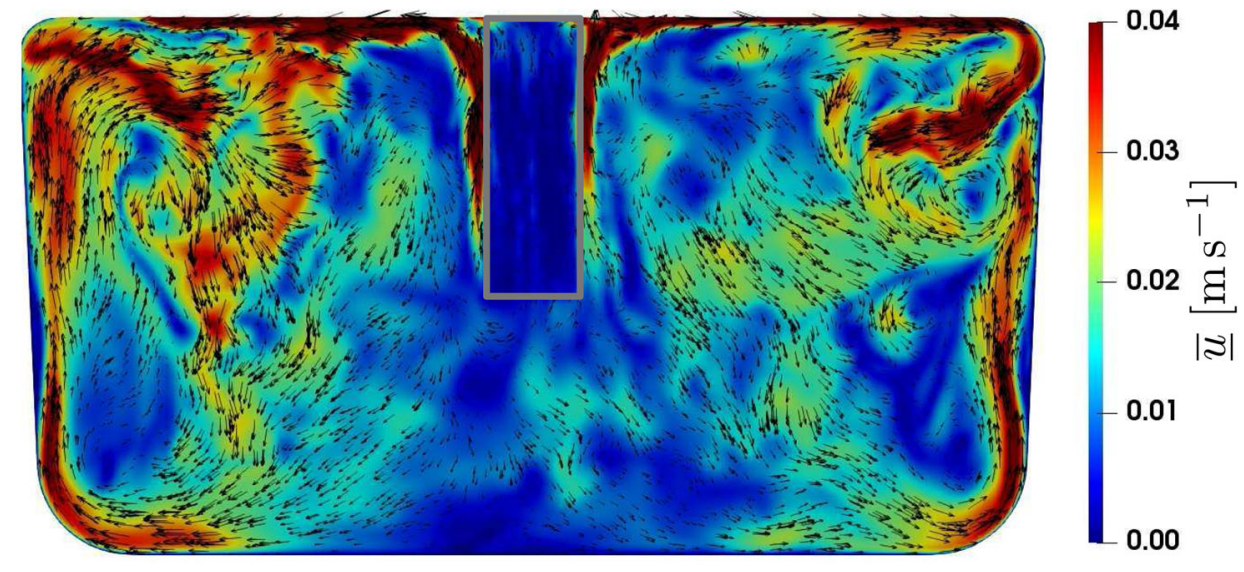

(a)
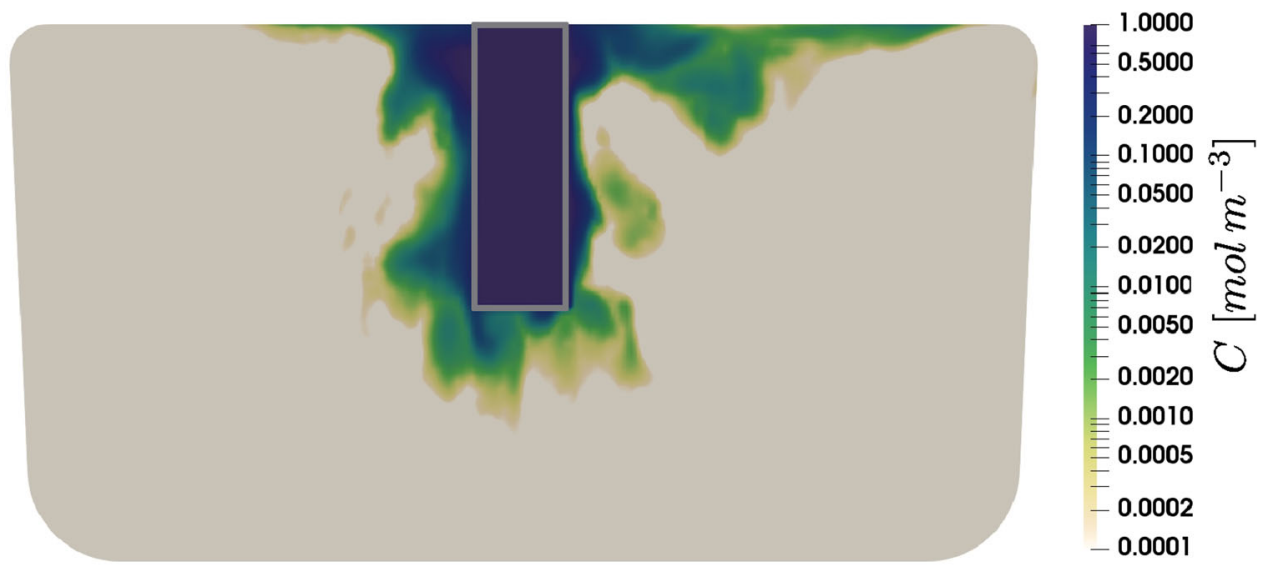

(b)

Fig. 4. (a) Instantaneous velocity field $\underline{u}$ and (b) concentration of carbon in the central plane of the induction crucible furnace at $t=10 \mathrm{~s}$, when the filter is removed from the melt. The grey box denotes the location of the filter.

The instantaneous velocity field in the central plane of the induction crucible furnace is presented in Fig. 4a, revealing that the flow field consists of many turbulent structures. Additionally, it is clear that the melt velocity is high close to the walls of the filter, in comparison with the flow field presented by 


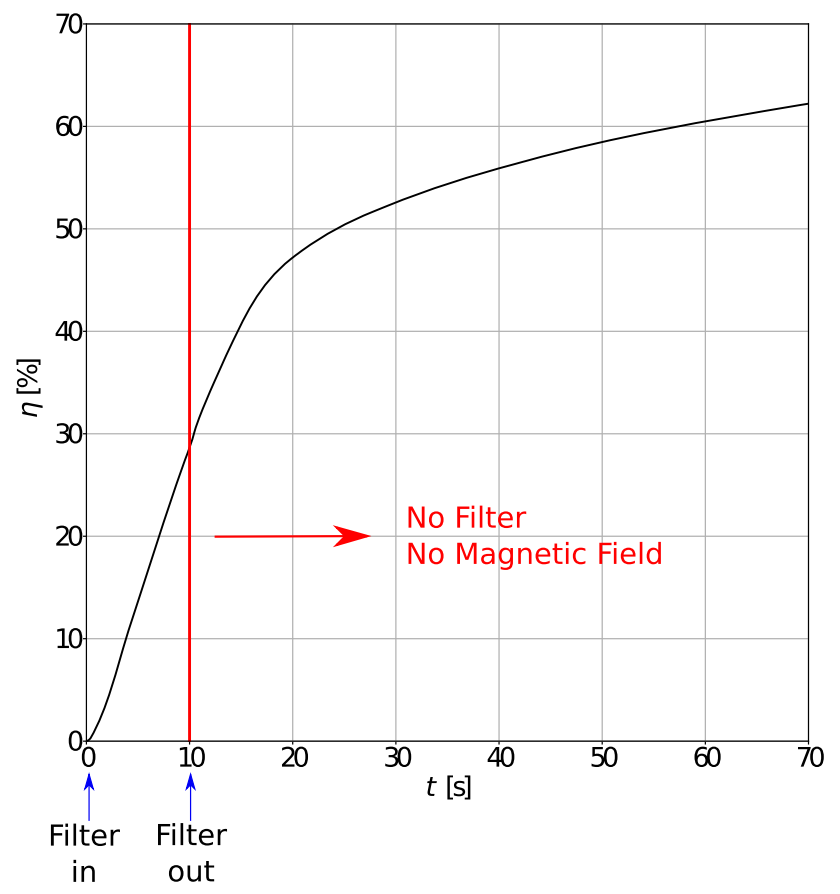

Fig. 5. Increase of steel cleanliness during the simulation time due to the effect of carbon monoxide bubbles arising on inclusions.

Asad et al. ${ }^{21,22}$ This is caused by flotation of large equivalent particles close to the filter. This effect plays a significant role in enhancing transportation of carbon from the filter into the melt, by increasing the velocity close to the filter. Furthermore, it can be seen that the velocity is high at some positions inside the filter. This is caused by fast flotation of particles inside the filter.

Figure $4 \mathrm{~b}$ shows the concentration of $\mathrm{C}$ in the flow field after $t=10 \mathrm{~s}$. Here it is clear that the concentration of $\mathrm{C}$ is higher close to the filter compared with regions far from the filter. This explains the larger equivalent particle size close to the filter.

The effect of the creation of carbon monoxide bubbles on the melt cleanliness can be seen in Fig. 5. $\eta$ represents the ratio of the initial number of inclusions to the number of inclusions captured by the free surface. As mentioned above, the magnetic field was disabled and the filter removed from the melt after $10 \mathrm{~s}$. After removal of the filter, the steel melt needs about $10 \mathrm{~min}$ to solidify, as found experimentally. ${ }^{3,23}$ This means that inclusions can still float up to the free surface after $t=10 \mathrm{~s}$ as well. From Fig. 5, it is evident that the number of inclusions reaching the free surface increases with time. After $10 \mathrm{~s}$, about $30 \%$ of the introduced inclusions have been captured by the free surface. In the simulation performed without considering bubble creation, $\eta$ is approximately equal to $1 \%$ after $10 \mathrm{~s}$, confirming the significant effect of bubble creation on the cleanliness of the steel melt. As can be seen, inclusions can still reach the free surface after the magnetic field has been disabled (after $10 \mathrm{~s})$. This improves the cleanliness of the melt (specified by $\eta$ ). In the work of Storti et al., ${ }^{23}$ a similar filtration experiment was conducted and samples of solidified steel were analyzed, revealing that $60-95 \%$ of the inclusions were removed from the melt. This value depends strongly on the filter type. From the present results, it is clear that $\eta$ increases to above $60 \%$, in agreement with experimental data. The present simulation results indicate that bubble formation can indeed explain the noticeable difference between the experimental results of Storti et al. ${ }^{23}$ and Asad et al. ${ }^{22}$

\section{CONCLUSIONS}

A new model is introduced to consider creation of carbon monoxide bubbles on alumina inclusions in an induction crucible furnace. The model can describe the growth of the carbon monoxide bubbles by considering transportation of carbon from the immersed carbon-bonded filter to $\mathrm{Al}_{2} \mathrm{O}_{3}$ and the first-order reaction between carbon and oxygen. The numerical results show that such reaction between carbon and oxygen has a considerable effect on the cleanliness of the melt. Here, it is found that about $30 \%$ of the inserted inclusions are removed after $10 \mathrm{~s}$ of simulation time. Moreover, it is shown that the bubble size increases quickly closer to the filter because of the high concentration of carbon. This leads to a high rising velocity of inclusions, increasing the melt velocity close to the filter wall.

In further studies, this numerical model must be extended to consider the interaction between inclusions. Moreover, a possible experimental setup will be used to validate the numerical model.

\section{ACKNOWLEDGEMENTS}

The authors would like to thank the German Science Foundation (DFG) for supporting the scientific work in terms of the Collaborative Research Centre "Multi-Functional Filters for Metal Melt Filtration-A Contribute towards Zero Defect Materials" (CRC 920 B06). The authors are grateful to Enrico Storti, Steffan Dudczig, and Eric Werzner for support.

\section{REFERENCES}

1. L. Zhang and B.G. Thomas, ISIJ Int. 43, 271 (2003).

2. L. Zhang, JOM 65, 1138 (2013).

3. S. Dudczig, C.G. Aneziris, M. Dopita, and D. Rafaja, Adv. Eng. Mater. 15, 1177 (2013).

4. C.G. Aneziris, S. Dudczig, J. Hubálková, M. Emmel, and G. Schmidt, Ceram. Int. 39, 2835 (2013).

5. E. Baake, A.Mühlbauer, A. Jakovičs, and W. Andree, Metall. Mater. Trans. B 26, 529 (1995).

6. R. Schwarze and F. Obermeier, Modell. Simul. Mater. Sci. Eng. 12, 985 (2004).

7. A. Umbrashko, E. Baake, B. Nacke, and A. Jakovičs, COMPEL Int. J. Comput. Math. Electr. Electron. Eng. 24, 314 (2005).

8. H. Barati, M. Wu, A. Kharicha, and A. Ludwig, IOP Conf. Ser. Mater. Sci. Eng. 143, 12 (2016).

9. D. Musaeva, V. Ilin, E. Baake, and V. Gea, Magnetohydrodynamics 51, 771 (2015).

10. E. Baake, A. Umbrashko, and A. Jakovičs, Arch. Electr. Eng. 54,425 (2005). 
11. A. Umbrashko, E. Baake, B. Nacke, and A. Jakovičs, Metall. Mater. Trans. B 37, 831 (2006).

12. P. Buliski, J. Smolka, S. Golak, R. Przyucki, M. Palacz, G. Siwiec, J. Lipart, R. Biaecki, and L. Blacha, Appl. Therm. Eng. 124, 1003 (2017).

13. V. Bojarevics, A. Roy, and K.A. Pericleous, Magnetohydrodynamics 46, 339 (2010).

14. M. Kirpo, A. Jakovičs, E. Baake, and B. Nacke, Magnetohydrodynamics 45,439 (2009).

15. M. Kirpo, A. Jakovičs, B. Nacke, and E. Baake, COMPEL Int. J. Comput. Math. Electr. Electron. Eng. 27, 377 (2008).

16. M. Kirpo, Modeling of Turbulence Properties and Particle Transport in Recirculated Flows. Ph.D. thesis, University of Latvia (2008).

17. M. Ščepanskis, A. Jakovičs, E. Baake, and B. Nacke, Steel Res. Int. 86, 169 (2015)

18. M. Ščepanskis, A Jakovičs, E. Baake, and B. Nacke, Magnetohydrodynamics 48, 677 (2012).

19. M. Sčepanskis, A. Jakovičs, E. Baake, and B. Nacke, Int. J. Multiph. Flow 64, 19 (2014).

20. M. Ščepanskis, A. Jakovičs, and E. Baake, J. Phys. Conf. Ser. 333, 012 (2011).

21. A. Asad, C. Kratzsch, S. Dudczig, C.G. Aneziris, and R. Schwarze, Int. J. Heat Fluid Flow 62, 299 (2016).

22. A. Asad, E. Werzner, C. Demuth, S. Dudczig, A. Schmidt, S. Ray, C.G. Aneziris, and R. Schwarze, Adv. Eng. Mater. 19, 1700085 (2017).
23. E. Storti, S. Dudczig, A. Schmidt, G. Schmidt, and C.G. Aneziris, Steel Res. Int. 88, 1700142 (2017).

24. E. Storti, Functionalization of Carbon-Bonded Ceramic Foam Filters with Nano-scaled Materials for Steel Melt Filtration. Ph.D. thesis, Technische Universität Bergakademie Freiberg (2018).

25. A. Schmidt, A. Salomon, S. Dudczig, H. Berek, D. Rafaja, and C.G. Aneziris, Adv. Eng. Mater. 19, 1700170 (2017).

26. D. Rzehak, Beschleunigte Entkohlung von Stahlschmelzen im Vakuum durch Kombination von Sauerstoff und Metalloxiden. Ph.D. thesis, Technischen Hochschule Aachen (2013).

27. M. Cournil, F. Gruy, P. Gardin, and H. Saint-Raymond, Chem. Eng. Process. 45, 586 (2006).

28. S. Yang, S.M. Dammer, N. Bremond, H.J.W. Zandvliet, E.S. Kooij, and D. Lohse, Langmuir 23, 7072 (2007).

29. D. Lohse and X. Zhang, Rev. Mod. Phys. 87, 981 (2015).

30. F.C. Campbell. Metals Fabrication: Understanding the Basics. ASM International (2013). ISBN 9781627080194.

31. P.L. Jones, S. Taylor, S. Nakai, and J. Jennings, Electrical Engineer's Reference Book, 6th ed., ed. M.A. Laughton and D.J. Warne (Oxford: Newnes, 2003), pp. 1-38.

32. J. Smagorinsky, Mon. Weather Rev. 91, 99 (1963).

33. H. Kim, J. Gyu Kim, and Y. Sasaki, ISIJ Int. 50, 678 (2010).

34. A. Asad, K. Chattopadhyay, and R. Schwarze, Mater. Trans. B (2018). https://doi.org/10.1007/s11663-018-1343-3.

35. R.I.L. Guthrie, Engineering in Process Metallurgy (Oxford Science Publications, Clarendon Press, 1992). ISBN 9780198562221. 